Trinity University

Digital Commons @ Trinity

Human Communication and Theatre Faculty

Research

Human Communication and Theatre

3-2011

\title{
Sensemaking and Relational Consequences of Peer Co-worker Deception
}

Erin M. Bryant

Trinity University, ebryant@trinity.edu

Patricia M. Sias

Follow this and additional works at: https://digitalcommons.trinity.edu/hct_faculty

Part of the Theatre and Performance Studies Commons

\section{Repository Citation}

Bryant, E. M., \& Sias, P. M. (2011). Sensemaking and relational consequences of peer co-worker deception. Communication Monographs, 78(1), 115-137. doi: 10.1080/03637751.2010.542473

This Post-Print is brought to you for free and open access by the Human Communication and Theatre at Digital Commons@ Trinity. It has been accepted for inclusion in Human Communication and Theatre Faculty Research by an authorized administrator of Digital Commons @ Trinity. For more information, please contact jcostanz@trinity.edu. 
Running head: PEER COWORKER DECEPTION

Sensemaking and Relational Consequences of Peer Coworker Deception

\author{
Erin M. Bryant \\ Arizona State University \\ Patricia M. Sias \\ Washington State University
}

Citation:

Bryant, E. M., \& Sias, P. (2011). Sensemaking and relational consequences of peer coworker deception. Communication Monographs, 1, 115-137. doi:

10.1080/03637751.2010.542473

All correspondence should be directed to the primaryauthor at ebryant@trinity.edu 


\section{Sensemaking and Relational Consequences of Peer Coworker Deception}

Peer coworker relationships are those "between employees at the same hierarchical level who have no formal authority over one another" (Sias, 2009, p. 58). Peer interaction comprises the majority of workplace communication (Comer, 1992; Sias \& Perry, 2004), and is central to the negotiation of meaning in organizations (Kunda, 1992). The quality of peer relationships is linked to important outcomes such as job satisfaction, organizational commitment, and the amount and quality of information employees receive from coworkers (Bottger \& Chew, 1986; Kirsch, 2000; Sias, 2005). Healthy peer relationships provide employees with emotional and task-related support and encourage effective job performance and individual well-being (Cahill \& Sias, 1997). At the same time, “organizational relationships are among the most frequently cited sources of intense emotion" at the workplace and destructive coworker relationships are often more stressful than actual job requirements (Waldron, 2000, p. 66).

Trust is an important component in peer coworker relationship growth and deterioration (Bullis \& Bach, 1989; Sias \& Cahill, 1998). Relationship growth is accompanied by increased trust and self-disclosure (Sias \& Cahill, 1998), whereas relationship deterioration involves decreased trust and regression toward depersonalized communication. Sias, Fix, Heath, Perry, and Silva (2004) found betrayal such as deception can provoke the deterioration of workplace friendships. Their study, however, did not address the complexities of coworker deception, such as how deceived employees make sense of deceptive acts and how such sensemaking affects peer coworker relationships. The present study was designed to fill these voids.

\section{Deception}

The term deception refers to acts by which a person alters or misrepresents information to communicate a false sense of reality to others (Knapp \& Comedena, 1979; Metts, 1989). 
Deception is typically considered an aversive behavior (Kowalski, Walker, Wilkinson, \& Sharpe, 2003) that harms relationships and destroys trust by violating "the presumption of truth that underlies most communicative interactions" (Burgoon, Buller, Floyd, \& Grandpre, 1996, p. 725). Despite its potentially harmful effects, deception is quite common (Camden, Motley, \& Wilson, 1984). Self-report studies indicate the average person lies in one out of every five social interactions (DePaulo, Kashy, Kirkendol, Wyer, \& Epstein, 1996) and is completely truthful in only 38 percent of his or her statements (Turner, Edgley, \& Olmstead, 1975).

Although deception is often equated with lying, "there is more to deception than meets the lie" (Hopper \& Bell, 1984, p. 300). People might deceive using outright verbal falsification (i.e., lying); however, they might also use more covert forms of concealment such as manipulating the environment or concealing aspects of the truth (Ekman, 1985). Hopper and Bell (1984) developed an expanded construct of deceptive communication that includes fictions (e.g., tall-tales and white lies), playings (e.g., tricks and jokes), lies (e.g., verbal dishonesty), crimes (e.g., cons, conspiracies, and cover-ups), masks (e.g., evasion, back-stabbing, and twofacedness), and unlies (e.g., distortion and misrepresentation). This broadened conceptualization of deception includes any act in which a person knowingly attempts to mislead others.

Research has examined the outcomes and correlates of discovered deception in personal relationships (e.g. Jang, Smith, \& Levine, 2002; McCornack \& Levine, 1990; Planalp \& Honeycutt, 1985), as well as self-reported motives for lying (DePaulo \& Kashy, 1998; DePaulo et al., 1996). These studies indicate people deceive for many reasons, including self-protection, saving face for another person, protecting an interpersonal relationship, and accomplishing individual goals (Metts, 1989). Some even consider deception as an indicator of communication competence that allows people to manage relational boundaries (Derlega, Metts, Petronio, \& 
Margulis, 1993; Petronio, 1991), censor negative thoughts, and maintain a sense of independence within a relationship (Cole, 2001; Saxe, 1991; Solomon, 1993).

A person's understanding of a deceptive act, however, is complex and biased based on their role as the deceiver or the deceived (Gordon \& Miller, 2000). Perpetrators tend to make situational attributions for their negative behavior, whereas observers and victims often attribute negative behaviors to the personality of the actor (Baumeister, Wotman, \& Stillwell, 1993; Gilbert, 1995; Gordon \& Miller, 2000). Accordingly, it is necessary to consider how perceptual factors might impact the attributions made in response to deception (Jehn \& Scott, 2008). Our study focuses exclusively on exploring how the deceived party makes sense of peer coworker deception by analyzing narrative accounts of discovered deception in coworker relationships.

\section{Making Sense of Coworker Deception}

As Weick (1995) explained, "The concept of sensemaking is well named because, literally, it means the making of sense" (p. 4). When humans engage in sensemaking, they "structure the unknown" (Waterman, 1990, p. 41), focusing largely on developing an understanding of why an event happened. They do so by using past experience, existing frameworks, information, or some combination of these, to explain an event in such a way that the event makes sense. As this conceptualization indicates, individuals engage in sensemaking when faced with uncertain, equivocal, ambiguous or surprising events (Weick, 1976, 1995; Louis, 1980), such as being deceived. The discovery of deception in personal relationships often produces negative emotions (McCornack \& Levine, 1990) and high levels of uncertainty (Planalp \& Honeycutt, 1985), which might provoke sensemaking to assign meaning that reduces uncertainty regarding the deceiver and their actions. Existing research has centered on deception 
in romantic relationships and non-work friendships; however, we know little about how deceived employees experience and make sense of coworker deception.

Events involving workplace relationships are likely to generate particularly intense emotions. As Weick (1995) explained, “In organizational settings, even though relationships may be short-lived, they are also often close, intense and interdependent ... This could mean that organizational life generates stronger feelings, both positive and negative, than is true of other settings" (p. 48). Moreover, sensemaking is more likely to be triggered by events that evoke negative emotions than those that evoke positive emotions. In sum, individuals are likely highly motivated to make sense of acts of coworker deception. Assumptions and interpretations made during sensemaking, whether accurate or merely plausible, should also affect the sensemaker's response to being deceived. Accordingly, an understanding of the relational impacts of coworker deception requires an understanding of how deceived parties interpret acts of deception.

People rely on many elements when making sense of an event, including perceptual frameworks, ideology, and premises that guide decision-making (Weick, 1995). With respect to making sense of deception, interpersonal communication research indicates that people rely on such elements as they specifically relate to the act's degree of truthfulness (Bavelas, Black, Chovil, \& Mullet, 1990; Metts, 1989), its consequences (Bryant, 2008; Knapp \& Comadena, 1979) or importance (Jang et al., 2002; McCornack \& Levine, 1990), the liar's intent or motives (DePaulo et al., 1983; Kowalski et al., 2003; Vangelisti \& Young, 2000), its intended beneficiary (Bryant, 2008; DePaulo \& Kashy, 1998; Hample, 1980; Lindskold \& Walters, 1983; Seiter, Bruschke, \& Chunsheng, 2002), and the degree to which it indicates relational devaluation (Kowalski et al., 2003 ). Deceived individuals might therefore behave very differently depending 
on whether they perceive the deception as a malicious and outright fabrication with serious implications or a trivial and harmless fib.

Similar factors are likely also relevant to workplace deception. The workplace context, however, may include features that make sensemaking of peer coworker deception somewhat unique from other forms of personal relationships. As Weick (1995) cautioned, “...the social context is crucial for sensemaking because it binds people to actions that they then must justify, it affects the saliency of information, and it provides norms and expectations that constrain explanations" (p. 53). In other words, the sensemaking frameworks upon which individuals rely to interpret an event are created in, and constrained by, the social context - in this case, the organization. Employees in highly competitive work environments may, for example, possess different frameworks for interpreting deception than those in more supportive collaborative organizations. To address these issues, we examined the following research question:

RQ1: How do deceived individuals make sense of coworker deception?

\section{Deception's Impact on Peer Relationships}

We conceptualize relationships as categories of meaning constituted in interaction (Sigman, 1995). Relationships are not entities external to the relationship partners, but are mental creations that depend on communication for their existence and form. This conceptualization acknowledges the dynamic nature and relative uniqueness of various workplace relationships. Consistent with this conceptualization, scholars note that not all peer relationships are the same (Kram \& Isabella, 1985; Sias, 2009). In particular, Kram and Isabella (1985) identified three primary types of peer workplace relationships that vary with respect to the breadth and depth of communication between the partners. Information peer relationships are relatively superficial, characterized by low levels of trust and self-disclosure. Collegial peer relationships are 
friendships characterized by moderate levels of trust and increasing discussion of non-work related topics at a moderate level of intimacy. Special peer relationships are very close or best friendships involving a high degree of trust, intimacy and self-disclosure of both work and personal information (Kramer, 1994; Sias \& Cahill, 1998).

Because trust is a distinguishing characteristic of the peer relationship types, and deception represents a communicative betrayal of trust, coworker deception will likely negatively affect peer relationships. In fact, Sias and Perry (2004) found that betrayal was often responsible for the deterioration and eventual termination of workplace friendships (i.e., collegial and special peer relationships). That study focused only on deteriorated or terminated friendships, however, and deception likely does not affect all peer relationships in the same way. As Kowalski et al. (2003) noted, “...people and relationships seem to have evolved a mechanism that allows them to overcome feelings of negativity and resentment that stem from repeated exposure to others' aversive interpersonal behaviors" (p. 487). Relationships often survive hardships, betrayal, mental, and even physical abuse when both partners think that terminating the relationship would be more costly than repairing and maintaining it. Peer workplace relationships may therefore survive deception in many cases.

Peer workplace relationships are unique in that they are, in most cases, nonvoluntary relationships (Sias, Krone, \& Jablin, 2002). Management generally selects employees based on their ability to provide the skills and knowledge necessary for the company to succeed (Perrow, 1973). Thus, peer relationships are, at least initially, task-focused rather than relationshipfocused, and this task-focus must be maintained even with a disliked coworker. Working with a disliked coworker can be stressful, particularly when the coworkers' job tasks are highly interdependent such that each relies on the other to do their work (Weick, 1995). Coworkers 
might have unique ways of dealing with conflict because ending the relationship can be difficult, painful, and harm the partners' abilities to do their jobs. As a result, coworkers may choose to overlook minor transgressions. Again, the deceived party's sensemaking likely influences how the deception affects the relationship. To understand these issues, we examined the following: RQ2: How do deception and the deceived party's sensemaking of the deception affect peer coworker relationships?

\section{Method}

\section{Data Collection and Sample}

Fifty-eight coworker deception narratives were obtained via interviews with a convenience sample of 23 adults employed full-time (11 male, 12 female). Participants ranged from 23 to 58 years of age $(M=42)$ and self identified as Caucasian $(n=16)$, Hispanic/Latino $(n$ =3), Asian/Pacific Islander $(n=3)$, and African American $(n=1)$. With respect to education, the sample was diverse yet slightly over-educated: six participants possessed a high school degree or less, seven attended some college, seven graduated college, and three held advanced degrees. Participants had worked an average of 6.7 years (range $=3$ months -25 years) at their current organization, and included sales workers $(n=4)$, restaurant service workers $(n=3)$, service technicians $(n=3)$, healthcare practitioners $(n=3)$, administrative workers $(n=2)$, researchers $(n=2)$, a construction worker $(n=1)$, an architect $(n=1)$, an educator $(n=1)$, a dispatcher $(n=$ $1)$, a hairstylist $(n=1)$, and a mortgage broker $(n=1)$. The sample represented a range of organization sizes: less than 100 employees $(n=6), 100$ to 1,000 employees $(n=7)$, and more than 1,000 employees $(n=10)$.

We used a snowball sampling method by asking members of our social network to identify friends or coworkers who might be willing to participate in a research study about 
workplace relationships. Identified individuals were contacted via telephone or e-mail to arrange an interview. Eight participants were recruited through the initial set of contacts, and six of these individuals provided the contact information of another friend or family member who was willing to participate. We reached theoretical saturation at 50 narratives (20 interviews) at which point no substantial new information surfaced (Glaser \& Strauss, 1967). Interviews took place at a location of each participant's choosing and lasted, on average, 50 minutes. Interviews were audio taped and transcribed in their entirety, producing 158 single-spaced pages of data. Participants provided written consent in accordance with our university's IRB policies.

A semi-structured interview protocol facilitated the production of narratives (see Appendix A) and provided participants the ability to contextualize their perspectives and provide a cohesive narration of their experience (Tracy, Lutgen-Sandvik, \& Alberts, 2006). Participants were asked to provide an account of an incident in which they were deceived by a coworker and include any information they felt was relevant. Participants were encouraged to provide as many narratives as they could recall, and follow-up questions were asked if important elements did not surface in participants' original narratives.

\section{Analytic Method}

Data were explored for common themes using analysis of narratives (Denzin, 1997;

Hones, 1998). People tend to organize their thoughts in terms of stories (Fischer, 1984; JohnsonCartee, 2005). Moreover, narratives provide specific explanations of causality, morality, and significance that illuminate an individual's interpretation of the event's meaning and the lessons he or she learned from it (Sias, et al., 2004). Analysis of narratives was, therefore, appropriate for examining sensemaking of coworker deception. 
According to Labov (1972), a narrative includes one or more of the following elements: an abstract (i.e., a short summary of the whole story), orientation (i.e., a description of the time, setting, and people involved), complicating action (i.e., events that triggered the climax), evaluation (the narrator's interpretation of the event and its consequences), resolution (the end result of the situation), and coda (statements that signal the end of a narrative and bring the discussion back the present moment in time). Our research questions were relevant to three narrative components. The complicating action and evaluation components addressed types of deception and sensemaking of deceptive acts (RQ1), and the resolution component addressed how actors resolve the complicating action (RQ2). Thus, our analysis explored general themes regarding the complicating action, evaluation and resolution of coworker deception narratives, using a constant comparison approach (Glaser \& Strauss, 1967).

A researcher unaffiliated with the study coded 12 narratives selected from transcripts to assess the coding reliability. The researcher was briefed on the distinctions between each theme and was asked to label each narrative within our analytic schema Coders achieved 100\% agreement on the complicating action, $88 \%$ agreement on evaluation, and $92 \%$ agreement on the resolution narrative components, indicating themes were both transparent and robust.

\section{Results}

The 58 narratives represent various incidents in which participants felt deceived by a coworker. Some narratives involve outright lies whereas others describe concealment, omission, back-stabbing, and other forms of deceptive communication. Although it would be possible to classify narratives using existing typologies of deception, we used the analysis of narratives approach to inductively construct themes. 
Narratives themes were distinguished primarily by the evaluation, rather than complicating action or resolution component. Many narratives, for example, involved a coworker who used deception to steal a client from the participant. These narratives received very different evaluations by participants making sense of the deception, despite possessing nearly identity complicating actions. Accordingly, we organized our analysis around the evaluation narrative component, primarily focusing on explaining the coworkers' motives for deception. Analysis revealed four primary deception narratives: corrupt system, CYA, personal gain, and personality trait. For each of these narrative types, we discuss the complicating action, details of the evaluation, and the resolution of the narratives. Table 1 summarizes the four narrative types. [Insert Table 1 here]

\section{Corrupt System Narratives}

Complicating Action. In corrupt system narratives $(n=8)$ participants blamed systemic company flaws for their coworkers' deceptive behavior. Two narratives involved a specific coworker and the remainder dealt with widespread deceptive practices. Participants reasoned their coworkers lied because their company ignored problems and placed undue stress on employees. For example, one participant claimed coworkers were forced to create fake excuses to avoid time-consuming tasks "because if you hit a snag at some point during the day, you're kind of screwed." He did not blame these employees because "everything stems from time and realistically a lot of that stuff probably wouldn't be an issue if people had more time to get things done." Thus, even honest coworkers might resort to deception when the company gives them an impossible workload.

Other participants explained that certain employees knew how to exploit the system's general tolerance of deception. A salesperson explained that his coworkers repeatedly "stole 
clients" by writing up contracts that were supposedly in his sales territory. He characterized this behavior as a breach of professional ethics, but also said it was deceptive because the coworkers acted collegially despite their secret actions, and then falsified excuses to justify why they took on clients outside of their territory.

Another participant described his organization's climate as one of interdepartmental warfare and competition where information was a form of ammunition. He explained, "there's [sic] so many potential problems that come up on any given day, and nobody wants to be the one to take fall for it is essentially what it boils down to." He claimed his supervisors actually encouraged workers to, "give as little information as possible to the other departments" and “intentionally be vague when sending the messages to other departments... so they can't trace it back to us if something goes wrong." This deceptive behavior was so widespread the participant found it difficult to pinpoint any one incident. He instead asserted that the strategic use of vagueness and omission was part of the organizational culture.

Evaluation. In corrupt system narratives, participants focused on evaluating their company rather than their coworkers. For example, a salesman who had been working in the industry for 24 years said that he had never seen an environment where such open and flagrant deception occurred throughout the organization. Explaining why a coworker stole his client, he pointed out that his coworker simply "knew the ropes" and figured out how to take advantage of the flawed system. He claimed, "The reason people would be deceptive is you get promoted. You get paid for performance and you get bonuses and cash rewards and all kinds of stuff for winning. And uh, you either win or you lose, and if you don't win you're kind of an outcast." In a different narrative, a participant explained that his coworkers lied because, "It's just the 
culture. So it's kind of like a survival of the fittest, but you've got to be a dirty dog to work there. In my opinion you can't be an honest person and survive at (company name removed)." Resolution. Corrupt system narratives tended to lack clear-cut resolutions because deception was considered a pervasive part of the organizational culture. An exception was the salesman who actually left the organization and claimed that working at the company was not an option “if you had any integrity at all you know. And that's why I quit. I just, I just said forget it I'm not gonna do this." Another participant was in the process of securing a job elsewhere and claimed, "I just got to hold on for 36 months, then I'm out of this."

In the remaining narratives, participants adapted their working style and learned to "hold [their] cards close to [their] chest to survive" in deceptive environments. As one stated, "You have to change your work style so people can't look over your shoulder and see what you're working on. Because if they do they could take it and try to steal it... you have to be deceptive in return." Participants also learned to avoid becoming overly involved with office politics and focused on surviving the system rather than fixing it. One explained, "I just go in and do whatever they tell me to. And I try to get out of there at 5 o'clock to get home so I can keep my sanity somewhat." This somewhat fatalistic perspective was shared by a different participant who claimed that the problem will never be fixed because upper management is an "Old Boys' Network" and "if they're going to solve the problems, they're the ones that have to do it. And they're just gonna let it go." Regardless of whether they quit or learned to survive, widespread deception in corrupt system narratives was said to produce an extremely stressful working environment for honest employees.

“CYA” Narratives 
Complicating Action: CYA narratives $(n=15)$ involved incidents in which a coworker made an honest mistake but then fabricated excuses to cover up their lack of performance. A few participants noted that the coworkers involved in these narratives misrepresented the truth, yet were hesitant to label the incident as deception. One participant explained, 'I don't know if it's dishonesty, but people cover their ass, I mean they CYA. They may not necessarily do what they're supposed to, so they do things to cover up some of their lack of performance." CYA narratives were especially prevalent in complex and fragmented organizations where participants felt it was easy to hide behind a larger group or point fingers at others to avoid personal blame.

Evaluation. In general, participants described CYA deception as a "natural" coping response to a difficult situation. As such, sensemaking focused on the circumstances that "forced" a coworker to misrepresent the truth despite a lack of malice. Deceptive coworkers were said to be "staying afloat" in a situation where they were "in over their head." One participant explained, “it's almost like a natural thing. You know, your first thing to do is to duck-and-cover... their form of duck-and-cover is to try to cover up what they did." Another explained that people simply got "too busy" and honestly forgot to perform a task "but then when it comes back to hit them their knee-jerk reaction is to cover up. You know, it's to save face or to do something to prevent getting in trouble." CYA deception was therefore said to be dishonest yet a somewhat understandable form of self-preservation.

In CYA narratives participants acknowledge the workplace context yet prominently noted their coworkers' role in the deception. Participants often explained that their organization is competitive and coworkers might fear they will be punished if they require aid or admit their mistakes. Most participants stressed that their coworkers were simply reacting to threatening 
circumstances of their own making. For example, a participant whose coworker lied to cover up not following company procedure explained,

Her laziness got her into trouble. And then she tried to survive and kind of stay afloat and had to try to cover her tracks because she knew she was sort of in the wrong in her approach. And so when you're about to get called on it, and you're already on thin ice, you're gonna try to figure out a way to cover up your tracks.

Although this narrative stressed that the coworker's laziness created the problem, the participant's switch from saying "she" to "you" suggests empathy for this behavior. Overall, participants evaluated that CYA deception was "not the end of the world" but that employees should be upfront about mistakes rather than covering them up.

Resolution. Many participants noted that their organizations' complexity and large size made it difficult to hold any one person accountable for their mistakes. One participant explained, "You can't just take it for granted that everybody is doing their own job because somebody is bound to drop the ball." Thus, one outcome of CYA deception was that employees lost trust in each other and increased efforts at monitoring the progress of important projects.

Some narratives CYA deception became a chronic problem that prevented participants from performing their jobs and negatively impacted their relationship with the deceptive coworker. In the remaining narratives, participants resolved the issue by altering their communication tactics. For example, one explained, "what I started doing was when I'd send information to this person, I'd copy their boss so that I had a paper trail. I quit doing it on the phone and did it by email. That way there was a documentation of the event." Another said that because she was having problems with the receptionists not paging her when patients arrived, "now I just have my patients check in and then come straight back and sit down in like our 
wheelchair area so I can see they are there and not have to wait for a page." These communication changes enabled participants to hold their coworkers more accountable, and minimized the frequency and consequences of CYA lies without any major relational distress.

\section{Personal Gain Narratives}

Complicating Action. Personal gain narratives $(n=24)$ were the most prevalent form of deception in the dataset. These narratives involved deception aimed at obtaining personal gain in the form of money, goods, power and status. Thirteen involved coworkers who were deceptive for financial or material gain such as stealing from the company or cheating the participant out of commission money. More mundane narratives involved coworkers taking food and inexpensive supplies from the company, or padding their paychecks (i.e., not working the full amount of paid hours). One participant, for example, reported that a coworker wanted free parts for a home computer and, "ordered computer parts under MY number, and when they'd come in in the evening he'd go down to the part shop and pick them up. And they'd show on MY inventory, but I never saw the parts." Another explained that it was very easy to steal in the restaurant business because, "when the customer orders a couple beers it's really easy to not ring it up, and if they are paying cash then you can just pocket that money and no one would know." Many of these narratives involved behaviors that could also be characterized as theft; however, participants strongly noted the extent to which their coworker deceived others in the process.

The remaining 11 narratives involved deception to gain power or status in the company. Several narratives involved subtle status positioning such as, "communicating progress in such a way that almost steals credit." Another participant discussed "gatekeeper" employees who withheld information from others to make themselves indispensable to the organization. Yet another described "a certain coworker that... that used to race falcons and has had tea with 
Stephen King, and you know what I mean? Just a person who’s an expert in everything” According to the participant, this coworker told tall-tales about his past to gain popularity. Participants stressed that these instances were not blatant lies, but rather, subtle attempts to distort, omit, or otherwise mislead others in a way that bolstered the deceptive coworker's image.

Other personal gain narratives involved deception in which the participant felt personally targeted. These deceptive acts represented direct or behind-the-back character attacks designed to bolster the coworker's position by discrediting the participant. One participant told of a coworker who "basically went to our boss and told him that I wasn't doing my job and that I was mistreating the other workers, which was ridiculous. I mean, I just got called into a meeting at Starbucks and get attacked by her in front of my boss." The participant said that not only were the allegations untrue, but the coworker never mentioned the problem to her before reporting it to the boss. A physical therapist reported a similar incident in which a coworker attempted to discredit her by sending a local expert an email that negatively and inaccurately, attacked the participant's therapy methods. Although the email did not mention her by name, the participant resented that her coworker misrepresented her methods and then had the audacity to use the expert's response as ammunition to gain status in the organization.

Evaluation. Participants generally evaluated personal gain deception as premeditated and motivated by greed, selfishness, and insecurity. Although some participants noted that personal gain deception was exacerbated by a competitive job market, the sensemaking process of personal these narratives focused primarily on the coworkers' actions. One participant, for example, noted that people sometimes feel like the "company or the boss owes them something," so out of greed they find ways to get the money or goods they think they are owed. 
The evaluation of personal gain narratives was also largely contingent upon who was the perceived target of a coworker's deception. Although the coworkers' actions in these narratives were described as "very dishonest," participants were not as bothered when they did not feel targeted. The narrative involving a coworker stealing computer parts using the participant's identification number exemplified this. Despite the coworker's blatant dishonesty, the participant was not particularly angry and explained, “I figured it didn't cost me anything. I just let management know, 'hey I'm getting all these parts on my inventory. You guys want them back. I don't have them, I never ordered them... you figure out what to do'." When the participants did not feel targeted by a coworker's deception they still noted that their coworker displayed a complete lack of concern for how their behavior might negatively impact others. One participant even described himself as collateral damage of a coworker's selfish and dishonest attempts to climb the organizational ladder.

Conversely, personal gain deception that specifically targeted participants evoked strong emotions and harsh evaluations. Participants said they were "very angry" and felt like they "got screwed" by their deceptive coworkers. One participant thought her coworker tried to make her look bad because, "she felt threatened. It all boils down to that really. I'm better at my job than her. I've done it longer. I make better tips. The manager left ME in charge. I think she wanted to take me down because she wanted my position so to speak."

The seriousness of deception's consequences (both actual and potential) also impacted participants' sensemaking of personal gain deception. One participant stated that his deceptive coworker got her way "on the sacrifice of like nine others" who had to deal with the consequences. The participant whose coworker sent an email about her therapy methods to an expert asserted, "It's almost like reporting abuse to someone." The fact that she felt grossly 
misrepresented by this coworker and had her professional credibility questioned in front of an expert led this participant to view the incident and coworker very negatively.

Resolution. Participants resolved incidents of chronic but untargeted deception (e.g., paycheck padding, subtle positioning) by reasoning that it is difficult to catch the guilty parties. Although they were unhappy with their coworkers' actions, participants provided little description of the resolution besides explaining that they dropped the issue because "everyone knows it happens, but it's not going to change so there's no point in fighting over it."

Deception that specifically targeted participants had more substantive resolutions. Interestingly, the dishonest coworkers succeeded in getting their way in many of these narratives. In the narrative of the coworker who stole computer parts, the participant indicated, "management didn't do a whole lot. They basically slapped him on the wrist" because he could not be easily or cheaply replaced. Similarly, a participant explained that the coworker who cheated him out of an account was "a long-term employee and my boss is his good friend, so I just dropped it." The participant's relationship with coworker, however, drastically changed. I still have communication with him because he's in the group and he's good friends with our boss and I don't need problems, [but] now I'm just careful about what I talk to him about. I don't talk to him freely about everything anymore... He was a good friend but now I just never know whether he will screw me over again. And if it weren't for work I would just be done with him.

Similarly, when a different participant discovered that her coworker was trying to discredit her, "it immediately affected our relationship, our work relationship." She claimed she still feels angry when she sees the coworker and talks to her only when required. Another claimed, "I never spent one minute communicating with them ever after that." 
Although participants were angry and hurt, several avoided directly confronting their coworker because doing so would create a hostile working environment. Still, only one of the five narratives involving a targeted personal attack lacked a description of how their relationship suffered following the deception. Most participants claimed they reduced their communication and relationship to a minimum level given the constraints of their organization. One participant whose job tasks were highly interdependent with their deceptive coworker's tasks actually quit her job to escape the toxic environment.

\section{Personality Trait Narratives}

Complicating Action. In 11 narratives, participants described deception arising from a coworker's problematic personality traits. These narratives involved two types of personality problems: minor problematic traits and major character flaws. The five narratives involving minor problematic traits arose due to conflicting personalities that caused the truth to get distorted. One participant explained, for example, "There's a guy in the office that wants to just be friends with everyone, which is fine. And then there's a guy in the office that always thinks he's right." The incident occurred because someone forgot to restock the office refrigerator and the "know-it-all guy" was said to "go crazy" because he took it personally. Another coworker (labeled the "mediator guy") lied in saying he agreed with this coworker's anger because he did not want to cause further problems. His misrepresentation of feelings conflicted with the participant's blunt personality and caused a confrontation between the three coworkers.

The six remaining narratives involved more blatant and malicious forms of dishonesty attributed to the coworker's seriously flawed character. One participant (a researcher), described a coworker who was caught falsifying data on a grant-funded study. Another participant told of a coworker who attempted to steal one of his long-term clients while he was out of town. As they 
talked about these coworkers, participants described other past encounters to contextualize their experience. In fact, these narratives contained some of the longest and most developed complicating actions in this study. One participant noted "there's so much history with this woman it's almost impossible to capture." Another began her narrative by saying, "I don't even know where to start... but we have this really shady guy at work that I will never trust again." In all six cases, the complicating actions involved a series of questionable behaviors from a coworker, usually leading to the description of a climatic act of deception.

Evaluation. Whereas participants' evaluation of personal gain narratives centered on a coworker's deceptive actions, personality trait narratives focused on a deceptive coworker's inherently flawed character and personality. When making sense of personality trait lies, participants made little or no reference to any external or organization factors that may have provoked their coworkers' behavior.

Participants evaluated minor problematic personality traits and major personality flaws differently. Participants did not think their coworkers with minor problematic traits were maliciously deceptive, but rather, could not help who they are. One participant explained that workers in a small office learn how to respect each other's personality quirks (e.g., a tendency to over react or exaggerate), even if that means not telling the complete truth. Participants did not condemn their coworkers for possessing these traits, but rather tried to avoid situations that might trigger or exacerbate their coworker's problematic personality traits.

In contrast, coworkers in major personality flaw narratives were said to possess serious character issues that led them to be blatantly and maliciously individuals. Rather than evaluating the deceptive behaviors, participants evaluated the deceptive people by labeling them "lazy," "shady," "sneaky," and "unbalanced." One participant claimed that some coworkers occasionally 
lie when they get really busy, but with one coworker, 'it doesn't matter how busy he is. He would do that... he would just reschedule that and put that off onto someone else even though it's his job to do it because that's how he is -- he's lazy." Participants made sense of these narratives by ignoring the organizational climate and external events that led to the deception and placing complete blame on the individual who told the lie.

Participants evaluated these deceptive acts and the people who committed them very harshly. The participant who described the "shady guy" stated, "personally, the guy really disgusts me and if I remember what he does I really don't want to talk to him." The participant whose coworker falsified data claimed the person was the "one bad apple in the bunch" and that, You would NEVER see this happening with anybody else. We DEFINITELY have very high integrity. I mean it's the sort of place where we're funded on grants, so we can't spend money on a bag of cookies for a meeting with grant money because that would, you know, be misusing it. So maybe it was that but, I really don't know. I mean really it makes you wonder if she was like a little unbalanced or something. I mean giving her own urine samples -- it's just weird.

This coworker's dishonesty had negative consequences because the entire study was ruined and the whole organization looked irresponsible for misusing grant funds. Other narratives involved heavy fines, damaged or lost property, and the loss of clients as the results of a coworker's dishonesty. Participants believed that the fact that coworkers purposely committed these acts with full knowledge of the problems it would cause was proof of their flawed personality.

Deceptive coworkers in major character flaw narratives were said to regularly engage in malicious acts of deception. One participant explained, "She personally attacked me and that's the part where I trust her as far as I can throw her. There's no way I'm investing important 
information in her... and it's not the first time it's happened. I'm just the next victim." Another participant made a similar claim in stating, "It wasn't just me she was targeting. It was a group of us that worked together and we talked about it. And so we warned each other -- this person is dishonest and trespasses." The words "target" and "victim" were prominent in major character flaw narratives, highlighting the extent to which participants held the deceivers personally responsible for their malicious dishonesty. Participants repeatedly emphasized that these coworkers not only did dishonest things, they were dishonest people.

Resolution. Resolutions of personality trait narratives varied depending on whether a coworker's dishonesty was evaluated as a minor personality trait or a major character flaw. Minor personality trait narratives lacked clear resolutions because the character traits were both trivial and ongoing. One participant explained that because she works in a small organization, “we're like a little family. You've got your first cousins, your weird aunts and uncles, your weird second cousins... we don't see eye-to-eye on much of anything, but that's fine. You just move on." Thus, many relationships were not ruined because the coworkers adapted and found ways to work together despite their different levels of bluntness and honesty. One participant explained "you know how to treat certain people at certain times. And you can say certain things to certain people... but with others, I mean, I can still be honest but I probably, I can only say so much before they're gonna break." Assuming their coworkers would not change, the participants altered their own behavior to maintain the relationships.

Major character flaw narratives, in contrast, reflected the harsh evaluations and strong emotions they evoked. All these narratives involved coworkers the participant barely knew and participants described attempting to avoid this person. Two participants completely disengaged from the relationship by circumventing the deceptive coworker despite continuing to work in 
same organization. One participant explained, "now we won't even ask her for stuff even for work related items because she doesn't give you the right information."

Only two serious character flaw narratives were resolved in a way that the participant maintained a functional relationship with their deceptive coworkers. These participants reduced communication to necessary work-related topics and explained, “you don't help the guy out with any kind of extra help. He is not, he's like the guy that comes in, does his work and goes home. We don't invite him out for functions." This participant explained that she is able to maintain a working relationship with this coworker because he does his job well, however,

You're always gonna have to rethink what you do because of the way he is. You have to think, is he really screwing me over or is he being genuine and needs help? But it's kind of like dealing with a person with a drug habit. You know, is he really straightening out or is he just getting ready to go buy some more drugs? Is he telling the truth this time?

\section{Interpretation and Discussion}

Consistent with Weick's (1995) concept of sensemaking, the narratives examined here indicate that coworker deception triggered uncertainty and negative emotions for the deceived parties. The sensemaking process produced interpretations, assumptions, and attributions that, consequently, affected coworker communication and coworker relationships in a number of important ways. We discuss the sensemaking process and relational consequences below.

\section{Making Sense of Coworker Deception}

Deceived employees made sense of coworker deception by focusing primarily on why their coworkers acted deceptively, and the four narrative types reflect different perceived motives. In corrupt system narratives, participants attributed coworker deception to organizational factors that required employees to deceive in order to survive and succeed. In 
CYA narratives, participants acknowledged their coworkers' role in the deception, but viewed it as a natural response to a threatening work situation. In personal gain narratives, participants explained their coworkers' actions were motivated by financial greed and status gains. Sensemaking in these narratives centered on the deceptive behavior, with little or no mention of organizational factors. Finally, participants made sense of personality trait narratives by attributing the deception to the deceiver's problematic personality. Participants spent little time discussing the actual lie and instead gave detailed and contextualized evaluations of the deceiver's character. In sum, the four narrative types represent a continuum of organizational and individual attributions anchored by corrupt system narratives that placed blame on the organization and personality trait narratives that placed responsibility on individuals.

Existing interpersonal research suggests that perspective affects how people judge deception (Gordon \& Miller, 2000), and our analysis aimed to provide greater understanding of workplace deception as experienced and made sense of by the deceived. Consistent with extant literature (e.g., Bryant, 2008; Camden et al., 1984; Di Battista, 1994), our data indicate that employees consider a number of elements when making sense of a coworker's deception. Lies perceived as having a selfish intent and severe personal consequences received very harsh evaluations, highlighting the importance of inferred motive as a primary element considered in the sensemaking and evaluation process of deception (e.g. Goffman, 1967; Seiter et al., 2002). Although participants rarely knew the exact reasons why their coworkers deceived them, narratives consistently involved an attempt to assign such motives as a way to make sense of what happened. Perceived motives might be particularly important in a workplace context because many coworker relationships lack the intimacy and trust that might lead people to make default assumption of altruism. 
Attribution theory (Heider, 1958) explains how people interpret or determine causes of their own, and other's behaviors, and informs our interpretation of participants' sensemaking of coworker deception. Specifically, the theory posits that individuals tend to attribute behavior to either internal or external causes, and identifies various errors people make while attributing causality. When observing others, people often fall prey to fundamental attribution error (Ross, 1977); that is, mistakenly assuming the behavior of someone else derives from internal causes such as personality, rather than external or situational factors. Our continuum's organizational anchors (i.e., corrupt system and CYA narratives) indicate that the fundamental attribution error may be less likely to be activated in workplace deception. Instead, the workplace context appears to play in integral role in deception as a sometimes culpable party. Along these lines, the organizations' perceived competitiveness (Pace \& Foules, 1989; Spitzberg \& Cupach, 1984) affected sensemaking of coworker deception, especially in corrupt system narratives. In these narratives, participants blamed coworker deception not on their coworker, but on organizational systems that reward dishonesty over integrity (e.g., "survival of the fittest," "old boys club"). Deceived employees responded to such deception by refusing to become personally invested in the corrupt system and by avoiding unnecessary interactions with other employees. Work, for these participants, became simply a way of earning a paycheck and they continued to work in an organization toward which they felt no personal connection by dissociating themselves from the organization. Attributing some or all of the blame for the deception on the organization appears to provide some protection for the coworkers' relationships. Notably, personal gain and personality trait narratives, which attributed causality to internal (individual) factors, involved more serious damage to the relationships than did corrupt system and CYA narratives. These 
results highlight the unique and complex nature of the sensemaking and attribution processes involved in workplace deception.

Workplace deception also appears to be unique from non-workplace deception with respect to perceptions of the deception's beneficiary and target. In a study of hypothetical romantic partner lying scenarios, Seiter et al's (2002) participants rated self-oriented or malicious lies as less acceptable than altruistic lies. It is therefore intriguing that when narrating their real experiences, our participants always assumed their coworker had selfish motives, even if said motives lacked malice. Perhaps individuals are less forgiving when discussing their perceptions of experienced as opposed to hypothetical deception. Relational context could also affect sensemaking of deception to the extent that partners might be more willing to assume altruism from a romantic partner than from a coworker. Similarly, perspective likely plays a large role in how people make sense of deception, such that they might make more selfprotective assumptions to justify their own use of deception, yet be unwilling to displace blame from other deceivers (Gordon \& Miller, 2000). It is also plausible that people are less able to detect altruistic lies. For example, if an employee provides a coworker with positive, but false, feedback, the target would likely not recognize the feedback as deceptive. It is therefore important to understand the perceptions of the deceived, even if those perceptions differ from the deceiver's rationale. The perceptions of the deceived are particularly useful for understanding deception's affect on relationships, as we discuss later.

Because the intended beneficiary of coworker deception was always assumed to be the deceiver, participants' sensemaking instead focused on interpreting the intended target of a lie. Participants evaluated deception more harshly when they were personally targeted, and were less troubled by general deception targeting the organization. This suggests participants failed to fully 
recognize the interdependency of an organizational system -- a lie that disrupts the system's efficiency will negatively impact all members of an organization (Pace \& Foules, 1989; Spitzberg \& Cupach, 1984). In fact, many narratives described deceptive coworkers as peripheral members of a highly-fragmented yet interdependent organization that forces employees to rely on coworkers they have never met. For example, deception sometimes occurred between coworkers who lived in separate regions yet dealt with each other through email or phone calls. Thus, organizational complexity appears to play a role in the sensemaking of coworker deception. Perhaps workers are more willing to deceive, or more suspicious of being deceived, when dealing with an "unknown" coworker with little or no established trust.

\section{Deception's Impact on Peer Coworker Relationships}

Two primary factors influenced deception's impact on peer relationships - the target and the severity of the deception. Consistent with our conceptualization of workplace relationships as constituted in communication, the impact of deception on peer relationships was primarily communicative. Deceived employees were more forgiving of coworkers whose deception targeted the organization rather than the participant (i.e., corrupt system, CYA, and minor personality flaw narratives). In such cases, participants altered their communication with the deceiver in ways designed to prevent or minimize future deception: copying others on emails, developing "paper trails" of interactions, and other tactics that held the coworkers more accountable for their actions. Participants in corrupt system and general personal gain narratives became more cautious when communicating with deceptive coworkers and avoided situations that they believed would exacerbate the potential for deception.

In contrast, deception perceived as premeditated, maliciously selfish, or directly and negatively affecting the participant seriously damaged relationships. The more severe incidents 
of personal gain and personality trait deception had particularly important impacts on the coworker relationships. Deceived employees interpreted these lies as serious violations of trust and maintaining relationships with deceptive coworkers in such situations was very difficult. Participants providing these narratives found ways to avoid deceptive coworkers, either engaging in the very minimum amount of communication necessary to accomplish tasks or terminating communication (and, therefore, the relationship) with the deceptive coworker completely. A few participants actually quit their jobs in the most extreme cases where deception was widespread or avoidance was not possible

In sum, deceived employees responded to the deception by making minor changes in their communication with deceptive coworkers, communicatively altering their relationship. Deceived employees reported increasing monitoring, leaving of paper trails, and making more substantive changes such as regressing to minimal levels of task-related communication with the coworker and completely terminating communication with the deceiver. Of particular interest are relationships that deteriorated to the point that participants claimed to have no relationship with deceptive coworkers despite their continued communication to perform work-related tasks. These could represent a form of what Sias, et al. (2004) referred to as depersonalization. Although Sias, et al. (2004) described depersonalization as a strategy to transform a coworker friendship into a strictly coworker relationship by removing its personal focus, our results indicate that depersonalization occurs between coworkers who never developed a friendship outside of work roles. Participants described avoiding their deceptive coworker unless job tasks required interaction, and no longer assumed any pretense of a cordiality or civility in their interactions. Thus, depersonalization might also serve as a de-escalation strategy via which 
nonvoluntary relationship partners transform a cordial information peer relationship (Kram \& Isabella, 1985) into a hostile yet functional relationship.

\section{Practical Implications}

The study's findings have several practical implications. As noted earlier, CYA lies were a prevalent form of deception. These lies were reportedly triggered when employees made honest mistakes and the organizational system and culture encouraged employees to lie to protect themselves from the consequences of admitting mistakes. We urge practitioners to consider how their organizational policies, culture, and climate may enable employee deception and work toward transforming their workplaces in ways that discourage, rather than encourage, deception. For example, much research has examined upward distortion (i.e., the propensity for employees to deceive by distorting information they provide to their supervisors either by lying or omitting facts) and this body of work indicates that supervisors who are not open to receiving negative information (e.g., they "shoot the messenger") encourage upward distortion (Dansereau \& Markham, 1987). Training supervisors to communicate more effectively and more openly with employees could provide employees with a safe space or outlet to seek help and repair mistakes without fear of repercussions. Employees make mistakes and providing a safe channel of open communication could prevent small missteps from becoming large problems when concealed. Our research suggests “corrupt system” organizations might also facilitate lateral distortion. Training employees to communicate more openly with one another could also enhance employees' willingness to admit mistakes or seek assistance when they've made a mistake.

Similarly, competition is common in organizations and it does not have to be destructive. However, many participants in our study asserted that coworker deception was a "survival of the fittest" behavior necessary to outperform coworkers, gain commission, or be promoted. Notably, 
participants often blamed their company for either creating or fostering this competitive environment, which ultimately destroyed coworker trust and hindered productivity. This suggests that organizational leaders might help prevent coworker deception by facilitating a collaborative environment that rewards cooperative success over individual achievement. If workers personally benefit from lying, removing these individual benefits would also likely remove a common motive for deceptive workplace behavior.

\section{Limitations and Suggestions for Future Research}

This study purposely examined how deceived individuals make sense of coworker deception. This focus was intentional based on existing research (i.e. Duck \& Pittman, 1994) that asserts the meaning of social behavior is contingent on how it is perceived by people. Moreover, our focus on the sensemaking practices of deceived employees was appropriate for examining deception's impact on coworker relationships. It did, however, provide a one-sided understanding of coworker deception. Exploring peer workplace deception from the perspective of the coworkers who committed these acts would likely provide a different, or at least more complex, understanding of motives. Future research should address this limitation by asking workers to provide accounts of instances in which they have been dishonest in their workplace.

In addition, this study examined how deception affected peer relationships, but did not explicitly consider how peer relationships might affect deception. Nonetheless, some of the narratives indicated that the nature of a peer relationship played a role in participants' interpretation of the deception. For example, many narratives involved coworkers the participant did not know well at the time of the deceptive act. Because trust is an important component of workplace friendship, it is possible that people lie more often, and more seriously, to coworkers to whom they feel little or no sense of interdependency or loyalty. In contrast, relationships in 
which deception involving a coworker who was considered a friend often survived minor acts of deception. Thus, our data are consistent with interpersonal research claiming relational partners develop a mechanism that allows relationships to survive minor transgressions (Kowalski et al., 2003). Moreover, these results indicate that peer relationships play a constitutive role in the sensemaking of coworker deception -- participants evaluated deception in light of appropriate behavior given the intimacy of a relationship. Future research should address these issues to obtain a more complex understanding of deception and peer relationships.

Future research should also examine how contextual factors such as the size, complexity, and fragmented nature of an organizational system affect deception among workers. Although all members of an organization experience some interdependency, our narratives suggest deception might be more prevalent in complex systems due to the lack of personal relationships and ties with coworkers. Thus, although interdependent on an organizational level, workers may be more prone to deception if they do not feel interdependency on an interpersonal level. Perhaps organizations can increase their efforts at establishing interpersonal bonds between coworkers in all the various aspects of the organization. Although not a focus of this study, some narratives suggest technology may play a role in workplace deception. Participants, for example, created email "paper trails" after discovering a coworker's deception. In addition, deception among "virtual" coworkers who have little or no physical contact may be unique. The role technology in workplace deception dynamics is, therefore, an important area for future research.

Many participants claimed that being deceived by a coworker provoked stress and negative emotions concerning their coworker or their organization. Left unaddressed, workplace stress can lead to feelings of alienation, emotional exhaustion, and depersonalization; a syndrome known as burnout (Maslach, Schaufeli, \& Leiter, 2001). Burnout can spread through an 
organization, increasing conflict and lowering employee productivity and morale (Tracy, 2009). Several participants in our study described depersonalizing a deceptive coworker, and in the case of corrupt systems, actually disengaging from the workplace. Given the debilitating impacts of stress and burnout on employees and organizations, future studies should examine more fully how coworker deception contributes to these conditions. It might be particularly fruitful to examine how peer coworker deception affects the entire organizational climate.

Finally, this study focused on deception among peer coworkers. Deception also occurs between supervisors and subordinate employees and future research should examine sensemaking of hierarchical deception - both upward and downward distortion. Such research would provide the more complete understanding of workplace deception and provide practitioners with knowledge necessary to implement programs and policies that minimize the destructive consequences of workplace deception. 


\section{References}

Baumeister, R. F., Wotman, S. R., \& Stillwell, A. M. (1993). Unrequited love: On heartbreak, anger, guilt, scriptlessness, and humiliation. Journal of Personality and Social Psychology, 64, 377-394.

Bavelas, J. B., Black, A., Chovil, N., \& Mullet, J. (1990). Equivocal communication. Newbury Park, CA: Sage.

Bottger, P. C., \& Chew, I. K. (1986). The job characteristics model and growth satisfaction: Main effects of assimilation of work experience and context satisfaction. Human Relations, $39,575-594$.

Bryant, E. (2008). Real lies, white lies, \& gray lies: Towards a typology of deception. Kaleidoscope, 7, 23-48.

Bullis, C., \& Bach, B. W. (1989). Are mentor relationships helping organizations? An exploration of developing mentee-mentor-organizational identifications using turning point analysis. Communication Quarterly, 37, 199-213.

Burgoon, J. K., Buller, D. B., Floyd, K., Grandpre, J. (1996). Deceptive realities: Sender, receiver, and observer perspectives in deceptive communication. Communication Research, 23, 724-748.

Cahill, D. J., \& Sias, P. M. (1997). The perceived social costs and importance of seeking emotional support in the workplace: Gender differences and similarities. Communication Research Reports, 14, 231-240.

Camden, C., Motley, M., \& Wilson, A. (1984). White lies in interpersonal communication: A taxonomy and preliminary investigation of social motivations. Western Journal of Speech Communication, 48, 309-325. 
Cole, T. (2001). Lying to the one you love: The use of deception in romantic relationships. Journal of Social and Personal Relationships, 18, 107-129.

Comer, D. R. (1992). Factors that make peers effective information agents for organizational newcomers. Journal of Management Systems, 4, 13-27.

Dansereau, F., \& Markham, S. (1987). Superior-subordinate communication: Multiple levels of analysis. In F. Jablin, L. Putnam, K. Roberts, \& L. Porter (Eds.), Handbook of organizational communication: An interdisciplinary perspective (pp. 343-388). Beverly Hills, CA: Sage.

Denzin, N. (1997). Interpretive ethnography: Ethnographic practices for the $21^{\text {st }}$ century. Thousand Oaks, CA: Sage.

DePaulo B. M., \& Kashy, D. (1998) Everyday lies in close and casual relationships. Journal of Personality and Social Psychology, 74, 63-79.

DePaulo, B. M, Kashy, D., Kirkendol, S., Wyer, M., \& Epstein, J. (1996) Lying in everyday life. Journal of Personality and Social Psychology, 70, 979-995.

DePaulo, B. M., Lanier, K., \& Davis, T. (1983). Detecting deceit in the motivated liar. Journal of Personality and Social Psychology, 45, 1096-1103.

Derlega, V. J., Metts, S., Petrinio, S., \& Margulis, S. T. (1993). Privacy regulation and vulnerability. In V. J. Derlega, S. Metts., S. Petrinio, \& S. T. Margulis (Eds.), Selfdisclosure (pp. 65-88). Thousand Oaks, CA: Sage.

Di Battista, P. (1994). Effects of planning on performance of trust-violating versus tactful white lies: How are familiar speech acts cognitively represented? Communication Studies, 45, 174-186. 
Duck, S., \& Pittman, G. (1994). Social and personal relationships. In M. L. Knapp \& G. R. Miller (Eds.), Handbook of interpersonal communication ( $2^{\text {nd }}$ ed., pp. 676-695). Thousand Oaks, CA: Sage.

Ekman, P. (1985). Telling lies. New York: W. W. Norton.

Fisher, W. (1984). Narration as a human communications paradigm: The case of public moral argument. Communication Monographs, 51, 1-22.

Gilbert, D. T. (1995). Attribution and interpersonal perception. In A. Tesser (Ed.), Advanced social psychology (pp. 192-242). New York: McGraw-Hill.

Glaser, B. G., \& Strauss, A.L. (1967). The discovery of grounded theory: Strategies for qualitative research. Chicago: Aldine.

Goffman, E. (1967). Interpersonal ritual: Essays on face-to-face behavior. NY: Pantheon Books. Gordon, A. K., \& Miller, A. G. (2000). Perspective differences in the construal of lies: Is deception in the eye of the beholder? Personality and Social Psychology Bulletin, 26, 46-55.

Hample, D. (1980). Purpose and effects of lying. The Southern Speech Communication Journal, 46, 33-47.

Heider, F. (1958). The psychology of interpersonal relations. New York: John Wiley \& Sons.

Hones, D. F. (1998). Known in part: The transformational power of narrative inquiry. Qualitative Inquiry, 4, 225-248.

Hopper, R., \& Bell, R. A. (1984). Broadening the deception construct. Quarterly Journal of Speech, 70, 288-302.

Jang, S. A., Smith, S. W., \& Levine, T. R. (2002). To stay or to leave? The role of attachment styles in communication patterns and potential termination of romantic relationships follow discovery of deception. Communication Monographs, 69, 236-252. 
Jehn, K. A., \& Scott, E. D. (2008). Perceptions of deception: Making sense of employee deceit. Journal of Business Ethics, 80, 327-347.

Johnson-Cartee, K. (2005). News narratives and news framing: Constructing political reality. Lanham, MD: Rowman \& Littlefield.

Knapp, M. L., \& Comadena, M. E. (1979). Telling it like it isn't: A review of theory and research on deceptive communications. Human Communication Research, 5, 270-285.

Kirsh, B. (2000). Factors associated with employment for mental health consumers. Psychiatric Rehabilitation Journal, 24, 13-21.

Kowalski, R. M., Walker, S., Wilkinson, A., \& Sharpe, B. (2003). Lying, cheating, complaining and other aversive interpersonal behaviors: A narrative examination of the darker side of relationships. Journal of Social and Personal Relationships, 20, 471-490.

Kram, K. E. \& Isabella, L. A. (1985). Mentoring alternatives: The role of peer relationships in career development. Academy of Management Journal, 28, 110-132.

Kramer, M. W. (1994). Uncertainty reduction during job transitions: An exploratory study of the communication experiences of newcomers and transferees. Management Communication Quarterly, 7, 384-512.

Kunda, G. 91992). Engineering culture: Control and commitment in a high-tech corporation. Philadelphia: Temple University Press.

Labov, W. (1972). Language in the inner city. Philadelphia: University of Philadelphia Press. Lindskold, S., \& Walters, P. (1983). Categories for acceptability of lies. Journal of Social Psychology, 120, 129-136.

Louis, M. (1980). Surprise and sensemaking: What newcomers experience in entering unfamiliar organizational settings. Administrative Science Quarterly, 25, 226-251. 
Maslach, D., Schaufeli, W. B., \& Leiter, M. P. (2001). Job burnout. Annual Review of Psychology, 52, 397-422.

McCornack, S. A., \& Levine, T. R. (1990). When lies are uncovered: Emotional and relational outcomes of discovered deception. Communication Monographs, 57, 119-138.

Metts, S., (1989). An exploratory investigation of deception in close relationships. Journal of Social and Personal Relationships, 6, 159-179.

Pace, R. W., \& Faules, D. F. (1989). Organizational communication. (2 $2^{\text {nd }}$ ed.). Englewood Cliffs, NJ: Prentice-Hall.

Perrow, C. (1973). The short and glorious history of organizational theory. Organizational Dynamics, 2, 2-15.

Petronio, S. (1991). Communication boundary management: A theoretical model of managing disclosure of private information between marital couples. Communication Theory, 4, 311 335.

Planalp, S., \& Honeycutt, J. M. (1985). Events that increase uncertainty in personal relationships. Human Communication Research, 11, 593-604.

Ross, L. (1977). The intuitive psychologist and his shortcomings: Distortions in the attribution process. In L. Berkowitz (Ed.), Advances in experimental social psychology (vol. 10; pp. 173-220). New York: Academic Press.

Saxe, L. (1991). Lying: Thoughts of an applied social psychologist. American Psychologist, 46, 409-415.

Seiter, J. S., Bruschke, J., \& Chunsheng, B. (2002). The acceptability of deception as a function of perceiver's culture, deceiver's intention, and deceiver-deceived relationship. Western Journal of Communication, 66, 158-180. 
Sias, P. M. (2005).Workplace relationship quality and employee information experiences. Communication Studies, 56, 375-396.

Sias, P. M. (2009). Organizing relationships: Traditional and emerging perspectives on workplace relationships. Los Angeles: Sage.

Sias, P. M., \& Cahill, D. J. (1998). From coworkers to friends: The development of peer friendships in the workplace. Western Journal of Communication, 62, 273-299.

Sias, P. M., Fix, B., Heath, R. G., Perry, T., \& Silva, D. (2004). Narratives of workplace friendship deterioration. Journal of Social and Personal Relationships, 21, 321-340.

Sias, P. M., Krone, K. K., \& Jablin, F. M. (2002). An ecological systems perspective on workplace relationships. In J. Daly \& M. L. Knapp (Eds.), Handbook of interpersonal communication ( $3^{\text {rd }}$ edition; pp. 615-642), Newbury Park, CA: SAGE.

Sias, P. M., \& Perry, T. (2004). Disengaging from workplace relationships: A research note. Human Communication Research, 30, 589-602.

Sigman, S. J. (1995). Order and continuity in human relationships: A social communication approach to defining “relationship." In W. Leeds-Hurwitz (Ed.), Social approaches to communication (pp. 188-200). New York: Guilford Press.

Solomon, R. C. (1993). What a tangled web: Deception and self-deception in philosophy. In C. Saarni \& M. Lewis (Eds.), Lying and deception in everyday life (pp. 30-58). New York: Guilford Press.

Spitzberg, B. H., \& Cupach, W. R. (1984). Interpersonal communication competence. Beverly Hills, CA: Sage.

Tracy, S. (2009). Managing burnout and moving toward employee engagement: A critical literature review and communicative approach toward reinvigorating the study of stress at 
work. In P. Lutgen-Sandvick \& B. Davenport Sypher (Eds.), The destructive side of organizational communication: Processes, consequences, and constructing ways of organizing (pp. 77-98). New York: Routledge.

Tracy, S. J., Lutgen-Sandvik, P., Alberts, J. (2006). Nightmares, demons, and slaves: Exploring the painful metaphors of workplace bullying. Management Communication Quarterly, 20, 148-185.

Turner, R., Edgley, C., \& Olmstead, G. (1975) Information control in conversations: Honesty is not always the best policy. Kansas Journal of Sociology, 11, 69-89.

Vangelisti, A., \& Young, S. (2000). When words hurt: The effects of perceived intentionality on interpersonal relationships. Journal of Social and Personal Relationships, 17, 393-424.

Waldron, V. R. (2000). Relational experience and emotion at work. In S. Fineman (Ed.), Emotion in organizations (pp. 64-82). London: Sage.

Waterman, R. J., Jr. (1990). Adhocracy: The power to change. Memphis, TN: Whittle Direct Books.

Weick, K. E. (1976). The social psychology of organizing. Reading, MA: Addison-Wesley.

Weick, K. E. (1995). Sensemaking in organizations. Thousand Oaks, CA: Sage.

Weiner, B. (1995). Judgments of responsibility: A foundation for theory of social conduct. New York: Guilford Press. 
Table 1: Summary of Narrative Themes

\section{Type of Narrative Complicating Action}

Corrupt System

Lying to survive or thrive in an organization with a dishonest culture.

CYA

Lying for financial, material, or social (i.e. status and power) gain

Personality Trait Conflicting personalities that facilitate dishonesty or lies that reflect a flawed and dishonest personality

\section{Evaluation}

Selfish and dishonest, but blame was placed on the corrupt organization.

Selfish but lacking malice. Blame was placed the coworker but the competitive organizational climate was noted

Maliciously selfish and driven by greed. Evaluations focused on the deceptive act and sensemaking depended upon severity and personal consequences on the participant

Evaluations focused on the deceptive coworker's character, rather than that person's actions. Sensemaking depended upon whether the coworker is slightly dishonest or severely dishonest.

\section{$\underline{\text { Resolution }}$}

Participants adapted by learning how to survive or by leaving the company.

Participants changed their communication tactics to hold deceptive coworkers accountable for their mistakes.

Lying coworkers tended to get their way without consequences. Lies that affected the participant led to relationship breakdown.

Participants changed communication tactics to avoid problems with slightly dishonest coworkers. Participants maintained a civil relationship with severely dishonest coworkers only when work required doing so. 